\title{
Influence of photon flux density and fluctuation on the nitrogen fixing Glycine $\max$ (L Merr)- Bradyrhizobium japonicum symbiosis in a controlled environment
}

\author{
JJ Drevon 1, JP Gaudillère 2, JP Bernoud 3, F Jardinet 3, M Evrard 3 \\ 1 INRA, Laboratoire de Recherches sur les Symbiotes des Racines, 1 Place Viala 34060 Montpellier-Cedex; \\ 2 INRA, Laboratoire de Physiologie Végétale, Domaine de la Grande Ferrade, 33140 Pont-de-la-Maye; \\ ${ }^{3}$ Rhône-Poulenc Agrochimie, 14, Rue P Baizet, 69009 Lyon, France
}

(Received 23 March 1990; accepted 16 January 1991)

\begin{abstract}
Summary - Nodulated soybeans, Glycine max (L Merr), were grown under 6 photon flux densities (PFD) from 0.35$1.03 \mathrm{mmol}$ photons $\mathrm{m}^{-2} \cdot \mathrm{s}^{-1}$, in order to determine the optimal light intensity for symbiotic nitrogen fixation in controlled environment. The nitrogenase activity $\left(\mathrm{C}_{2} \mathrm{H}_{2}\right.$ reduction) was highest at $0.68 \mathrm{mmol}$ photons $\mathrm{m}^{-2 .} \mathrm{s}^{-1}$ which also corresponded to the highest growth of plants and the biggest mass of nodules. The specific acetylene reducing activity was not affected by PFD, except at $1.03 \mathrm{mmol}$ photons $\mathrm{m}^{-2} \cdot \mathrm{s}^{-1}$, where it was much lower. Decreasing the PFD had no effect on nitrogenase activity during the following $24 \mathrm{~h}$. By contrast, an increase in PFD rapidly induced a significant decline of nitrogenase activity. At a similar PFD, the periodic light fluctuation was less beneficial than steady illumination for growth and nitrogen fixation. It is concluded that plant photosynthesis determines nodule mass which in turn determines the rate of nitrogen fixation. Nodule nitrogenase activity is not directly regulated by concurrent photosynthesis however, probably because of available photosynthate reserves and other regulatory mechanisms. Excess of light inhibits nitrogenase activity.
\end{abstract}

nitrogenase / nodules / photosynthesis / Rhizobium / Glycine max = soybean

Résumé - Influence de la densité et de la fluctuation du flux de photons sur la fixation symbiotique de l'azote par Glycine max-Bradyrhizobium japonicum. Dans l'objectif de déterminer l'intensité lumineuse optimale pour la fixation symbiotique de l'azote en milieu contrôlé, des sojas nodulés ont été cultivés sous 6 densités de flux de photons (DFP) comprises entre 0,35 et $1,03 \mathrm{mmol}\left(\right.$ photons) $\cdot \mathrm{m}^{-2} \cdot \mathrm{s}^{-1}$ (fig 1). L'activité nitrogénase (réduction de l'acétylène) est la plus élevée à $0,68 \mathrm{mmol}$ (photons) $\cdot \mathrm{m}^{-2} \cdot \mathrm{s}^{-1}$ (fig 2), densité de flux de photons qui correspond également aux croissances de plante et aux masses modulaires les plus élevées (fig 1). L'activité spécifique de réduction de l'acétylène par les nodosités n'est pas affectée par la DFP, excepté à 1,03 mmol(photons)•m- ${ }^{-2} \cdot \mathrm{s}^{-1}$ pour laquelle elle est plus faible (fig 2). La diminution de la DFP n'a pas d'effet sur l'activité nitrogénase pendant au moins $24 \mathrm{~h}$ (fig 3). Au contraire une augmentation de la DFP provoque rapidement une diminution significative de l'activité nitrogénase (fig 3). Pour une même DFP, un éclairement périodique comparé à un éclairement stable induit une croissance et une activité nitrogénase plus faibles (fig 2). La photosynthèse détermine donc la masse nodulaire qui en retour détermine la vitesse de fixation de l'azote. Cependant, l'activité nitrogénase nodulaire n'est pas directement régulée par la photosynthèse simultanée, probablement du fait de l'existence de réserves de photosynthats et d'autres mécanismes de régulation. Un excès de lumière inhibe spécifiquement la fixation d'azote.

nitrogénase / nodule / photosynthèse / Rhizobium / Glycine max = soja

Abbreviations : ARA, acetylene reducing activity; SARA, specific, ie per g nodule acetylene reducing activity; DW, dry weight; PFD, photon flux density. 


\section{INTRODUCTION}

Nitrogen fixation by soybean-Bradyrhizobium japonicum symbiosis depends upon photosynthesis that provides substrates for nodule maintenance, nitrogenase activity and incorporation of reduced nitrogen into amino acids (Salsac et al, 1984). The amount of nitrogen fixed during the growth cycle is generally limited by the photosynthetic activity of the macrosymbiont since it increases in plants grown in enriched $\mathrm{CO}_{2}$ atmosphere (Wilson et al, 1933; Hardy and Havelka, 1976) and varies with the intensity of shoot illumination (Bethlenfalway and Phillips, 1977; Antoniw and Sprent, 1978; Silsbury, 1981). The major effect of long-term manipulation of photosynthesis appears to be on the mass of nodules. Its effect on nodule nitrogenase activity, as measured by acetylene reducing activity ARA (Hardy et al, 1968) was less consistent: in the presence of an enriched $\mathrm{CO}_{2}$ atmosphere, the specific, ie per nodule, acetylene reducing activity (SARA) was higher than that in air for clover (Masterson and Sherwood, 1978), higher or similar for soybean (Hardy and Havelka, 1976; Finn and Brun, 1982; Williams et al, 1982), and similar or lower for pea (Masterson and Sherwood, 1978; Phillips et al, 1976). Thus Sheikholeslam et al (1980) suggested that the modification of photosynthesis affects nitrogen fixation by altering plant development rather than by changing the amount of energy translocated to the nodules.

In this study nodulated soybean plants were grown in a growth chamber under various light intensities to determine the critical photon flux density (PFD) for nitrogen fixation by this symbiosis in a controlled environment. Both steady and periodically fluctuating PFD were imposed. In order to monitor the short-term effect of photon flux density on the sARA, plants grown under a steady illumination were submitted to higher or lower steady photon flux densities over a 24-h period.

\section{MATERIALS AND METHODS}

\section{Biological material and growth conditions}

Soybean (Glycine max cv Hodgson) seeds were surface-sterilized, inoculated with Bradyrhizobium japonicum strain PJ 17 and grown in a liquid aerated nutri- ent medium as described previously (Kalia and Drevon, 1985). The conditions of cultivation in the growth chamber were $16 / 8 \mathrm{~h}$ light/dark cycles at $25 / 18^{\circ} \mathrm{C}, \approx$ $60 \%$ relative humidity. The serum bottle containing the nodulated root were wrapped in aluminium foil in order to prevent any direct effect of light on nodules.

Under steady illumination, plants were placed at increasing distances from a fixed beam carrying 13 $1000-W$ mercury vapor lamps. In the case of fluctuating illumination, plants were placed in a similar growth chamber and the only difference was that the beam carrying the light sources was displayed regularly at a speed of $5 \mathrm{~m} \cdot \mathrm{min}^{-1}$ (this device has been patented by Rhône-Poulenc Agrochimie Company and is manufactured by Retma Company, Lovie/Rhône, Givors, France). Photon flux densities (PFD; $1 \mathrm{mmol}$ photons $\mathrm{m}^{-2} \cdot \mathrm{s}^{-1}$ equals $\approx 70000 \mathrm{lux}$ ) were measured with a LiCor at the level of the second trifolioliate leaf; values are shown in figures and tables.

Plants received $1 \mathrm{mM}$ urea during the first $28 \mathrm{~d}$ of cultivation, otherwise plants under high intensities might have suffered a transient detrimental nitrogen deficiency (Williams and Phillips, 1980).

\section{Nodule nitrogenase activity measurement}

In this work, the nitrogenase catalyzed ARA was assayed in situ in closed vessels according to previously described experimental conditions (Kalia and Drevon, 1985). Gas samples of inner incubation atmosphere were taken 20 and 40 min after the acetylene injection. Ethylene and acetylene concentration were monitored on a Girdel 30 gas chromatograph (porapak T column, $1.2 \mathrm{~m}$ long, $3.2 \mathrm{~mm}$ diameter; $\mathrm{N}_{2}$ carrier gas $30 \mathrm{ml} \cdot \mathrm{min}^{-1}$; oven temperature $80^{\circ} \mathrm{C}$ ).

The ARA was measured on 42-45-d-old plants when they were still at a similar developmental stage, ie 5 leaves, and had a maximum sARA according to previous observations by Kalia and Drevon (1985) on hydroponically grown soybeans. The temperature in the root environment was $28^{\circ} \mathrm{C}$.

Relevant ARA data could be obtained for these hydroponically-grown soybeans without an open flow system; indeed, with a flowing gas stream, no significant decline in nitrogenase activity $\left(\mathrm{C}_{2} \mathrm{H}_{2}\right.$ reduction) of hydroponically-grown soybean was induced by acetylene (Weisz and Sinclair, 1987; Drevon et al, 1988). This observation contrasts with those obtained by a similar method with plants grown on perlite (Minchin et al, 1986).

\section{Dry weight of plants and nodules were measured after $48 \mathrm{~h}$ at $80^{\circ} \mathrm{C}$}

Statistical analyses were performed either by 2-way analysis of variance for the comparison of data at a given light intensity, or by regression and covariance 
analysis for the significance of light effect on plant and nodule parameters in the intervals of 0.35 to 0.68 $\mathrm{mmol}$ photons $\mathrm{m}^{-2} \cdot \mathrm{s}^{-1}$ and of $0.68-1.03 \mathrm{mmol}$ photons $\mathrm{m}^{-2} \cdot \mathrm{s}^{-1}$.

\section{RESULTS}

\section{Long-term response to photon flux density}

In the absence of PFD fluctuation, the maximum growth of soybean was under $0.68 \mathrm{mmol}$ photons $\mathrm{m}^{-2} \cdot \mathrm{s}^{-1}$ (fig 1). The highest mass of nodules was also observed on plants grown in presence of this density of the photon flux. Indeed nodule mass increased from $0.14 \mathrm{~g} \mathrm{DW} \mathrm{pl}^{-1}$ at 0.35 mmol photons $\mathrm{m}^{-2} \cdot \mathrm{s}^{-1}$ to $0.59 \mathrm{~g} \mathrm{DW} \mathrm{pl}^{-1}$ at 0.68 mmol photons $\mathrm{m}^{-2} \cdot \mathrm{s}^{-1}$ (fig 1). This increase of nodule mass was mostly due to a higher individual nodule mass (table I). It was highly correlated with plant growth $(r=0.99)$ which confirms the above-mentioned reports on the long-term effect of altered photosynthesis on nodulation.

The highest ARA was observed on plants grown under $0.68 \mathrm{mmol}$ photons $\mathrm{m}^{-2} \cdot \mathrm{s}^{-1}$ (fig 2). From a regression analysis of the data in figure 1 and in replicated similar experiments (data not shown), it can be extrapolated that the optimal

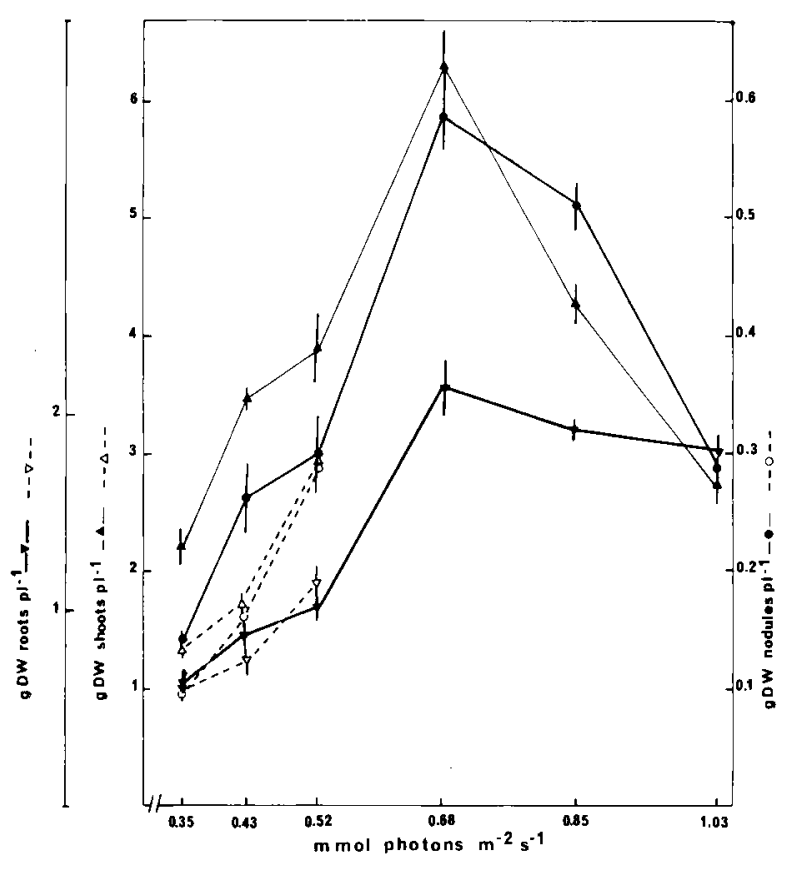

Fig 1. Influence of steady photon flux density on soybean growth of shoots $(\Delta)$, roots $(\nabla)$ and nodules $(\bullet)$ and fluctuating photon flux density on soybean growth of shoots $(\Delta)$, roots $(\nabla)$ and nodules $(O)$. Data are means of 543 -d-old plants for each growth illumination.
Table I. Influence of steady photon flux density on nodulation of soybean. Data are means \pm standard deviation of 5 replicates. Mean individual nodule mass was obtained by dividing total nodule mass per plant shown in figure 1 , by number of nodules per plant in this table. Plants were 43-d old.

\begin{tabular}{lll}
\hline $\begin{array}{c}\text { mmol Photons } \\
m^{-2} . s^{-1}\end{array}$ & No nod.pt-1 & $\begin{array}{c}m g(D W) \\
n o d^{-1}\end{array}$ \\
\hline & & \\
0.35 & $207 \pm 67$ & 0.68 \\
0.43 & $233 \pm 83$ & 1.12 \\
0.52 & $231 \pm 84$ & 1.29 \\
0.68 & $334 \pm 98$ & 1.77 \\
0.85 & $277 \pm 84$ & 1.85 \\
1.03 & $77 \pm 22$ & 3.68 \\
\hline
\end{tabular}

PFD for soybean symbiotic nitrogenase activity was very close to $0.7 \mathrm{mmol}$ photons $\mathrm{m}^{-2 . \mathrm{s}^{-1}}$. Above the optimal PFD, the ARA declined drastically, thus at $1.03 \mathrm{mmol}$ photons $\mathrm{m}^{-2 .} \mathrm{s}^{-1}$ it was $4 \%$ of the ARA at $0.68 \mathrm{mmol}$ photons $\mathrm{m}^{-2.2} \mathrm{~s}^{-1}$ (fig 2).

By contrast, the SARA (ARA per g nodule) was diversely affected by PFD and varied greatly from one experiment to another. On some days it was higher at suboptimal PFD than at optimal PFD, while on other days the effect was reverse. Consequently the mean data for each PFD in various experiments were not significantly different except at $1.03 \mathrm{mmol}$ photons $\mathrm{m}^{-2 .} \cdot \mathrm{s}^{-1}$, where it was always very low (fig 2). This detrimental effect of high PFD was greater for nitrogenase activity (which was only $8 \%$ of the opti-

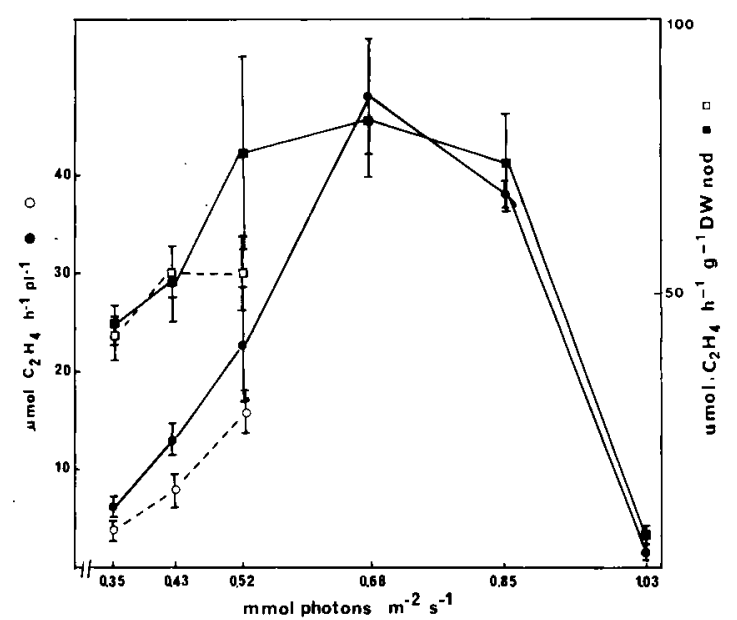

Fig 2. Influence of steady photon flux density on soybean root nodule nitrogenase activity $\left(\mathrm{C}_{2} \mathrm{H}_{2}\right.$ reduction) per plant (O) and per $\mathrm{g}(\mathrm{DW})$ nodules (D), and fluctuating photon flux density on soybean root nodule nitrogenase activity $\left(\mathrm{C}_{2} \mathrm{H}_{2}\right.$ reduction) per plant (O) and per g DW ( $\square$ ). Data are means and SD of 542 -d-old plants for each growth illumination. 
mal ARA), than for nodule mass or plant growth which were respectively $48 \%$ and $44 \%$ of the optimal values (fig 1).

\section{Short-term effects of photon flux density}

In studying the short-term effect of various illuminations, 20 plants grown under $0.52 \mathrm{mmol}$ photons $\mathrm{m}^{-2} \cdot \mathrm{s}^{-1}$ were distributed randomly into 4 groups of 5 plants each. One group was maintained under this illumination; 3 other groups were transferred under $0.20,0.40$ and 0.80 mmol photons $\mathrm{m}^{-2} \cdot \mathrm{s}^{-1}$. Temperature was maintained at $25^{\circ} \mathrm{C}$ during a complete diurnal cycle and during the previous $24 \mathrm{~h}$ to avoid any nodule perturbation due to temperature change (Schweitzer and Harper, 1980).

\section{Diurnal cycle}

The ARA assays performed at different times over a 24-h period revealed some fluctuation during the diurnal cycle (fig 3 ). The optimal activity was observed between $6-12 \mathrm{~h}$ after the be-

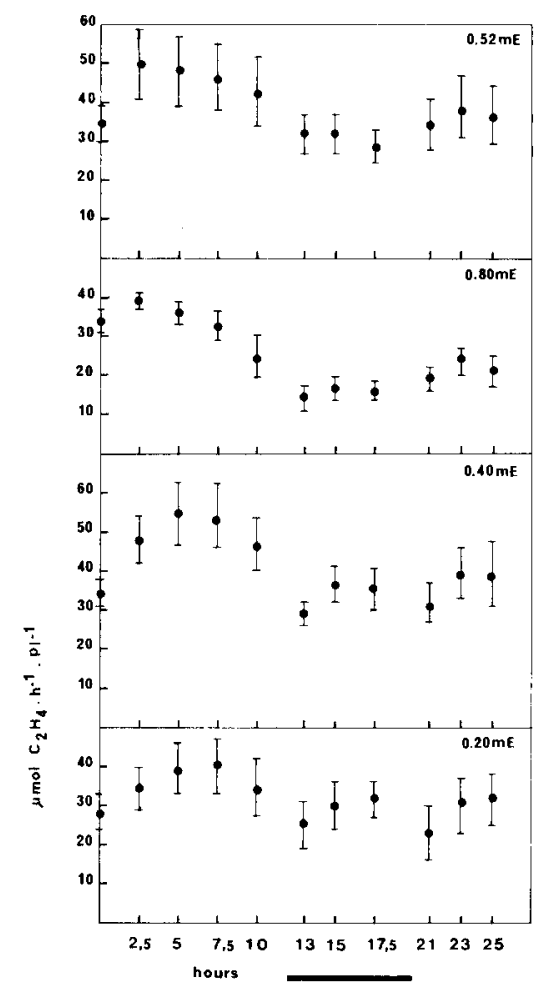

Fig 3. Changes in nitrogenase activity $\left(\mathrm{C}_{2} \mathrm{H}_{2}\right.$ reduction) following the transfer of nodulated soybeans from $0.52 \mathrm{mmol}$ photons $\mathrm{m}^{-2 \cdot \mathrm{s}^{-1}}$ to higher and lower photon flux densities. Data are means \pm SD of 5 replicates. The ARA was repeatedly measured on similar plants. Plants were $45-d$ old. The black line in the horizontal axis represents the dark period. ginning of the light period. It decreased before the beginning of the dark period during which the activity remained at a constant level. The ratio of maximum/minimum rates of nitrogenase activity during the diurnal cycle varied between 1.351.45 under $0.20,0.40$ and $0.52 \mathrm{mmol}$ photons $\mathrm{m}^{-2} \cdot \mathrm{s}^{-1}$.

\section{Change of light intensities}

Removing plants from $0.52 \mathrm{mmol}$ photons $\mathrm{m}^{-2.2} \mathrm{~s}^{-1}$ to 0.40 and $0.20 \mathrm{mmol}$ photons $\mathrm{m}^{-2 . \mathrm{s}^{-1}}$ had no short-term effect on nodule activity (fig 3). Therefore, nodule nitrogenase activity was not directly dependent on photosynthesis, probably because of available substrate reserves.

Removing plants from $0.52-0.80 \mathrm{mmol}$ pho-

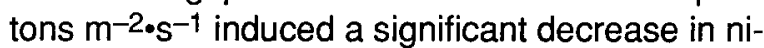
trogenase activity (fig 3 ). The decline was detected as soon as $150 \mathrm{~min}$ after the plants were exposed to the new environment. Thus between 9 and 11.30 am, the ARA increase was only $16 \%$ under $0.80 \mathrm{mmol}$ photons $\mathrm{m}^{-2} \cdot \mathrm{s}^{-1}$ compared with $\approx 40 \%$ in control. After $25 \mathrm{~h}$, the nitrogenase activity under $0.80 \mathrm{mmol}$ photons $\mathrm{m}^{-2} \cdot \mathrm{s}^{-1}$ was only $64 \%$ of its initial value, although in other treatments it was at least similar. The lowest ARA was observed at the end of the light period, when nodule activity of plants under $0.80 \mathrm{mmol}$ photons $\mathrm{m}^{-2} \cdot \mathrm{s}^{-1}$ was $50 \%$ lower than that of plants maintained under $0.52 \mathrm{mmol}$ photons $\mathrm{m}^{-2} \cdot \mathrm{s}^{-1}$. A similar negative effect of increase of PFD on ARA was observed after exposure to $0.85 \mathrm{mmol}$ photons $\mathrm{m}^{-2} \cdot \mathrm{s}^{-1}$ of soybeans grown at 0.68 (data not shown) which was close to optimal PFD growth of soybean with $\mathrm{N}_{2}$.

\section{Influence of light fluctuation}

At 0.35 and $0.43 \mathrm{mmol}$ photons $\mathrm{m}^{-2} \cdot \mathrm{s}^{-1}$, ARA of plants under fluctuating PFD was lower. However, sARA at midday (fig 2) and its variation during the diurnal cycle (data not shown) were not affected by light fluctuation. The major effect of PFD fluctuation was on nodule mass which was $40 \%$ lower under fluctuating PFD than under constant similar PFD (fig 1). This might be a consequence of the lower growth of shoots under fluctuating PFD (fig 1); thus $\mathrm{g}(\mathrm{DW})$ shoot $\mathrm{pl}^{-1}$ was respectively 40 and $53 \%$ lower than that under steady PFD, although root growth was not apparently affected by light fluctuation. At 0.52

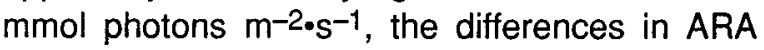


and root and nodule masses between the 2 treatments were not significant. Higher fluctuating PFD could not be monitored in our climatic cell because of the impossibility to fix more lamps on the beam.

\section{CONCLUSIONS}

The optimal light intensity for nitrogenase activity and growth of soybeans in climatic cells was 0.7 mmol photons $\mathrm{m}^{-2} \cdot \mathrm{s}^{-1}$, which confirms previous observations on soybean (Williams and Phillips, 1980; Williams et al, 1982; Walsh et al, 1987) and pea (Bethlenfalway and Phillips, 1977). Consequently this level of light intensity would be required to study symbiotic $\mathrm{N}_{2}$ fixation in the absence of photosynthesis limitation under artificial conditions.

For suboptimal illuminations, lower levels of nitrogenase activity were due to lower masses of nodules which suggests that nitrogen fixation was regulated by plant photosynthesis through the mass of nitrogen fixing tissue. But the specific activity of the tissue, ie the rate of nitrogenase activity per $\mathrm{g}$ nodule was independent of total plant photosynthesis (fig 2): therefore it would not be regulated by the concurrent shoot reduction of $\mathrm{CO}_{2}$. However, it should be pointed out that these results could possibly differ if nitrogenase inhibition by $\mathrm{C}_{2} \mathrm{H}_{2}$ (Minchin et al, 1986) which was not observed at the optimal illumination (Drevon et al, 1988), depended on light intensity.

ARA varied during the diurnal cycle (fig 3), which contrasts with previous observations of an absence of change in nodule activity during daynight cycle at constant temperature (Hardy et al, 1968; Fishbeck et al, 1973; Hart, 1976; Schweitzer and Harper, 1980; Williams et al, 1982; Walsh et al, 1987) but agrees with the work of Mederski and Streeter (1977). Since the decrease in nitrogenase activity preceded the dark period (fig 3), the diurnal variation of ARA did not relate directly to the shoot illumination. The maintenance of a high level of nodule activity during the dark period and during at least the $24 \mathrm{~h}$ following the transfer of plants to lower PFD (fig 3), which agrees with the observations of Williams et al (1982), is consistent with our above conclusion and with the suggestion of Schweitzer and Harper (1980) that a reserve pool of carbohydrate could be mobilized to support nodule activity in the absence of concurrent photosynthesis. However, our results with soybean differ from those obtained by Walsh et al (1987) according to which the ARA started to decline after $20 \mathrm{~h}$ exposure to darkness and that of Ryle (1988) who observed that exposing white clover to darkness affected nitrogenase activity within 30-60 min.

Putative regulators of nodule nitrogenase activity and the consequent flux of energy to these organs could be the plant nitrogen demand (Mederski and Streeter, 1977; Schweitzer and Harper, 1980; Silsbury, 1981) and the oxygen supply to the bacteroids (Bergersen, 1981; Sheehy et al, 1985; Drevon et al, 1987), although the mechanisms involved are still unknown.

Our observation of a decline in ARA after exposing plants to PFD higher than that applied during growth confirms the results of Williams and Phillips (1980) on soybeans transferred from 0.70 to $1.50 \mathrm{mmol}$ photons $\mathrm{m}^{-2 \cdot \mathrm{s}^{-1}}$, although our treatment was less stringent. This phenomenon may be specific to soybean since it was not detected on peas transferred from 0.50 to $0.80 \mathrm{mmol}$ photons $\mathrm{m}^{-2 . \mathrm{s}^{-1}}$ (Sheikholeslam et al, 1980) or french beans transferred from 0.04 to $0.11 \mathrm{mmol}$ photons $\mathrm{m}^{-2 . \mathrm{s}^{-1}}$ (Antoniw and Sprent, 1978). Its mechanism is not known; it differs with the early limitation of young plant nodulation by excess light (Fred et al, 1938; Orcutt and Fred, 1935) which has recently been attributed to $\mathrm{N}$ limitation of legumes depending exclusively on $\mathrm{N}_{2}$ fixation (Williams and Phillips, 1980). The limitation of plant nitrogen fixation and growth at supra-optimal PFD might be a consequence of $\mathrm{N}$ deficiency caused by this inhibition of nitrogenase activity by high PFD. This interpretation is consistent with the observation of very low specific nitrogenase activity of plants grown under $1.03 \mathrm{mmol}$ photons $\mathrm{m}^{-2 . \mathrm{s}^{-1}}$.

This phenomenon of $\mathrm{N}$ deficiency due to inhibition of $\mathrm{N}_{2}$ fixation by light intensities in the range of $1 \mathrm{mmol}$ photons $\mathrm{m}^{-2} \cdot \mathrm{s}^{-1}$ is generally not observed in field-grown plants although natural illumination would be as high as $1 \mathrm{mmol}$

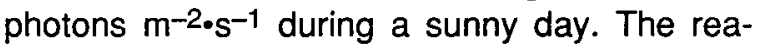
son for this apparent discrepancy with our results in an artificial environment may be that, under field conditions, plants receive complementary $\mathrm{N}$ from soil nitrification, and are grown in a more competitive density than in our experiments. An alternative explanation is that the observed inhibition under mercury vapor lamps may be caused by the spectrum composition of this light which differs from that of natural light. These hypotheses will be tested in further experiments. 
The PFD fluctuation had a negative effect on growth and nitrogen fixation at least at light intensities $<0.5 \mathrm{mmol}$ photons $\mathrm{m}^{-2 \cdot \mathrm{s}^{-1}}$. This may be due to a photoinhibitory effect of the temporarily high $\mathrm{PFD}$ on chloroplastic pigment concentration and chlorophyll fluorescence (Gaudillère et al, 1987).

\section{ACKNOWLEDGMENTS}

The a authors thank Dr Evans for supplying the strain PJ 17 and Dr Vidal for supplying the seeds that were used in this experiment. This work was supported by grant 1016 from EEC DG 6.

\section{REFERENCES}

Antoniw LD, Sprent JJ (1978) Growth and nitrogen fixation of Phaseolus vulgaris $L$ at two irradiances. II. Nitrogen fixation. Ann Bot 42, 399-410

Bergersen FG (1981) Root Nodules of Legumes: Structure and Functions. Research Studies Press, Chichester

Bethlenfalway GJ, Phillips DA (1977) Effect of light intensity on efficiency of carbon dioxide and nitrogen reduction in Pisum sativum L. Plant Physiol 60, 868-871

Drevon JJ, Kalia VC, Heckmann MO, Salsac L (1987) Influence of Bradyrhizobium japonicum hydrogenase on the growth of Glycine and Vigna spp. Appl Environ Microbiol 53, 610-612

Drevon JJ, Kalia VC, Heckmann MO, Pedelahore P (1988) In situ open-flow assay of acetylene reduction activity by soybean root-nodules: influence of acetylene and oxygen. Plant Physiol Biochem 26, 73-78

Finn GA, Brun WA (1982) Effect of atmospheric $\mathrm{CO}_{2}$ enrichment on growth, non structural carbohydrate content and root nodule activity in soybean. Plant Physiol 69, 327-331

Fishbeck K, Evans HJ, Boersma LL (1973) Measurement of nitrogenase activity of intact legume symbionts in situ using the acetylene reduction assay. Agron J 65, 429-433

Fred EB, Wilson PW, Wyss D (1938) Light intensity and the nitrogen hunger period in the Manchu soybean. Proc Natl Acad Sci USA 24, 46-52

Gaudillère JP, Drevon JJ, Bernoud JP, Jardinet F, Euvrard $M$ (1987) Effects of periodic fluctuations of photon flux density on anatomical and photosynthetic characteristics of soybean leaves. Photosynth Res 13, 81-89
Hardy RWF, Holstein RD, Jackson EK, Burns RC (1968) The acetylene-ethylene assay for $N_{2}$ fixation: laboratory and field evaluation. Plant Physiol 43, 1185-1208

Hardy RWF, Havelka UD (1976) Photosynthate as a major factor limiting nitrogen fixation by field-grown legumes with emphasis on soybean. In: Symbiotic Nitrogen Fixation in Plants (Nutman PS, ed) Cambridge University Press, London, 421-438

Hart Al (1976) A root chamber for measuring the acetylene reducing activity of intact soya-beans. N Z J Agric 199, 349-352

Kalia VC, Drevon JJ (1985) Variation in nitrogenase activity $\left(\mathrm{C}_{2} \mathrm{H}_{2}\right.$ reduction) during in situ incubation of root nodules of Glycine max (L) Merr. CR Acad Sci (Paris) 12, III, 591-596

Masterson CL, Sherwood MT (1978) Some effects of increased atmospheric carbon dioxide on white clover (Trifolium repens) and pea (Pisum sativum). Plant Soil 49, 421-426

Mederski HJ, Streeter JG (1977) Continuous automated acetylene reduction assays using intact plants. Plant Physiol 59, 1076-1081

Minchin FR, Sheehy JE, Witty JF (1986) Further errors in the acetylene reduction assay: effects of plant disturbance. J Exp Bot 37, 1581-1591

Orcutt FS, Fred EB (1935) Light intensity as an inhibiting factor in the fixation of atmospheric nitrogen by Manchu soybeans. J Am Soc Agron 277, 550-558

Phillips DA, Newell KD, Hassell SA, Felling CE (1976) The effect of $\mathrm{CO}_{2}$ enrichment on root nodule development and symbiotic $\mathrm{N}_{2}$ reduction in Pisum sativum. Am J Bot 63, 356-372

Ryle GJA (1988) The influence of host plant energy supply on nitrogen fixation. In: Physiological Limitations and the Genetic Improvement of Symbiotic Nitrogen Fixation (O'Gara F, Manian S, Drevon JJ, eds) Kluwer Academic Publishers, Dordrecht, 3-10

Salsac L, Drevon JJ, Zengbe M, Cleyet-Marel JC, Obaton $M$ (1984) Energy requirement of symbiotic nitrogen fixation. Physiol Vég 22, 509-521

Schweitzer LE, Harper JE (1980) Effect of light, dark and temperature on root nodule activity (acetylene reduction) of soybeans. Plant Physiol 65, 51-56

Sheely JF, Minchin FR, Witty JF (1985) Control of nitrogen fixation in a legume nodule: an analysis of the role of oxygen diffusion in relation to nodule structure. Ann Bot 55, 549-562

Sheikholeslam SN, Fishbeck KA, Phillips DA (1980) Effect of irradiance on partitioning of photosynthase to pea root nodules. Bot Gaz 141, 48-52

Silsbury $\mathrm{JH}$ (1981) $\mathrm{CO}_{2}$ exchange and dinitrogen fixation of subterranean clover in response to light level. Plant Physiol 67, 599-602 
Walsh KB, Vessey JK, Layzell DB (1987) Carbohydrate supply and $\mathrm{N}_{2}$ fixation in soybean: the effect of varied daylength and stem girdling. Plant Physiol 85, 137-144

Weisz PR, Sinclair TR (1987) Regulation of soybean nitrogen fixation in response to rhizosphere oxygen. I. Role of nodule respiration. Plant Physiol 84, 900905

Williams LE, Phillips DA (1980) Effect of irradiance on development of apparent nitrogen fixation and photosynthesis in soybean. Plant Physiol 66, 968972

Williams LE, Dejong TE, Phillips DA (1982) Effect of changes in shoot carbon-exchange rate on soybean root nodule activity. Plant Physiol 69, 432436

Wilson PW, Fred EB, Salmon MR (1933) Relation between carbon dioxide and elemental nitrogen assimilation in leguminous plants. Soil Sci 35, 145165 